\title{
Oridonin enhances the radiosensitivity of lung cancer cells by upregulating Bax and downregulating Bcl-2
}

\author{
SIRUI LI ${ }^{1}$, DAN SHI ${ }^{2}$, LIANGYU ZHANG ${ }^{1}$, FANG YANG $^{1}$ and GUANGHUI CHENG ${ }^{2}$ \\ ${ }^{1}$ Department of Medical Oncology, Daqing Oilfield General Hospital, Daqing, Heilongjiang 163111; \\ ${ }^{2}$ Department of Radiation, China-Japan Union Hospital of Jilin University, Changchun, Jilin 130033, P.R. China
}

Received October 4, 2016; Accepted June 22, 2017

DOI: $10.3892 /$ etm.2018.6803

\begin{abstract}
Oridonin is an active component of the traditional Chinese herb Rabdosia rubescens. The present study aimed to evaluate the antitumor effects of oridonin on human non-small cell lung cancer (NSCLC) cells and explore whether oridonin could enhance their radiosensitivity. Oridonin was demonstrated to inhibit the proliferation of SPC-A-1 and HCC827 lung cancer cells in a time- and dose-dependent manner, which was detected using the MTT assay. In addition, pretreatment with oridonin for $24 \mathrm{~h}$ prior to irradiation was identified to enhance the radiosensitivity of SPC-A-1 cells. Furthermore, the levels of apoptosis regulator BAX (Bax) and apoptosis regulator $\mathrm{Bcl}-2$ (Bcl-2) were detected by western blotting analysis. The results demonstrated that the level of Bax was increased and the level of Bcl-2 was decreased in SPC-A-1 cells treated with oridonin and irradiation compared with the group that received irradiation alone. These results indicate that oridonin may have a novel application as a radiosensitizing agent for the treatment of human NSCLC.
\end{abstract}

\section{Introduction}

Non-small cell lung cancer (NSCLC) is a disease with high incidence and mortality rates (1). Adenocarcinoma, squamous cell carcinoma and large cell carcinoma are the three common types of NSCLC $(2,3)$. In patients with lung cancer, $85-90 \%$ of cases are diagnosed as NSCLC (4). Compared with small cell carcinoma, the growth of NSCLC is slower (2). The clinical symptoms of NSCLC include fever, chest pain, shortness of breath, coughing and bloody sputum $(4,5)$. Clinically, NSCLC is typically treated with surgery, chemotherapy, radiotherapy, immunotherapy and combination therapy (6). Radiotherapy is frequently used in combination with chemotherapy for the treatment of NSCLCs if surgery alone is not possible $(6,7)$.

Correspondence to: Dr Guanghui Cheng, Department of Radiation, China-Japan Union Hospital of Jilin University, 126 Xiantai Street, Changchun, Jilin 130033, P.R. China

E-mail: chengguanghui686@163.com

Key words: oridonin, radiation, lung cancer, Bax, Bcl-2
Radiation can be used to induce NSCLC cell death and can relieve the symptoms caused by NSCLC, including breathing problems and swelling (8). Additionally, radiation therapy can be used to kill lung cancer cells that have metastasized to the other part of the body, such as the bones (7).

Although radiotherapy is an important cancer treatment, it can cause side effects, including neurotoxicity, nephrotoxicity, myelosuppression, nausea and vomiting (9). Radiation kills tumor cells and normal cells alike, which leads to limitations in its clinical application (10). Therefore, the combination of certain auxiliary anticancer drugs and radiotherapy has become an area of interest for cancer research. The optimal radiotherapy-anticancer drug combination should enhance the antitumor effects and reduce radiation-induced side effects.

Oridonin is an active kaurene diterpene that is derived from the traditional Chinese herb Rabdosia rubescens, which possesses antitumor activity and exhibits little toxicity (11). It has been reported that oridonin has antiproliferative and apoptosis-inducing effects on cells from various types of cancer, including colon cancer (12), gastric cancer (13), prostate cancer (14), laryngeal cancer (15), lung cancer (16), breast cancer (17) and gallbladder cancer (18). Murayama et al (19) demonstrated that oridonin induced radiosensitization in Chinese hamster V79 cells, alone or in combination with misonidazole (19). The radiosensitivity enhancement ratios of oridonin and misonidazole for hypoxic cells were 1.16 and 1.59 , respectively (19). In addition, the concurrent administration of Asian botanicals, including vincristine, and radiotherapy may increase the anticancer effects of therapies (20). However, the role of oridonin on the radiosensitivity of lung cancer cells remains unclear. The present study investigated whether oridonin could enhance the radiosensitivity of lung cancer cells and simultaneously to reduce the side effects of radiation, which would provide a novel method for the radiotherapy of human lung cancer.

\section{Materials and methods}

Cell lines and reagents. Human lung adenocarcinoma HCC827 (CRL-2868 ${ }^{\mathrm{TM}}$ ) cells were obtained from the American Type Culture Collection (Manassas, VA, USA). The human lung adenocarcinoma cell line SPC-A-1 (cat. no. YB-ATCC-4637) was purchased from Shybio Corporation (Shanghai, China) and was maintained in the 
laboratory of the Department of Medical Oncology, Daqing Oilfield General Hospital (Daqing, China). The HCC827 and SPC-A-1 cells were cultured in Dulbecco's Modified Eagles Medium supplemented with $10 \%$ fetal bovine serum (both HyClone; GE Healthcare Life Sciences, Logan, Utah, USA) at $37^{\circ} \mathrm{C}$ with $5 \% \mathrm{CO}_{2}$. Oridonin (cat. no. O9639) was purchased from Sigma-Aldrich (Merck KGaA, Darmstadt, Germany).

MTT assay. The inhibitory effect of oridonin on HCC827 and SPC-A-1 cells was measured using the MTT assay. Briefly, the cells were seeded into 96 -well plates at a density of $2 \times 10^{3}$ cells/well. The cells were pretreated with series of increasing oridonin concentrations $(0-80 \mu \mathrm{m})$ for different amounts of time $(24,48$ or $72 \mathrm{~h}$ ). Cells treated with $0.1 \%$ dimethyl sulfoxide (DMSO) were used as the negative control group. The cells were cultured for the indicated length and for further $4 \mathrm{~h}$ following MTT treatment $(5.0 \mathrm{mg} / \mathrm{l}, 20 \mu \mathrm{l})$ prior to testing. The crystals that had formed were dissolved with DMSO. Subsequently, the plates were read at a test wavelength of $490 \mathrm{~nm}$ and a reference wavelength of $570 \mathrm{~nm}$.

Clonogenic assay. Cells in the logarithmic phase of growth were irradiated with $6 \mathrm{MeV}$ X-rays, which were generated by a linear accelerator (Varian 2100C; Varian Medical Systems, Inc., Palo Alto, CA, USA). Briefly, the lung cancer cells were plated into $6 \mathrm{~cm}$ plates at a density of 5,000 cells/plate and irradiated at a dose of $0,2,4,6,8$ or $10 \mathrm{~Gy}$. The cultured medium was replaced every other day and the cells were cultured for 22 days. The cells were then fixed with paraformaldehyde ( $40 \mathrm{~g} / \mathrm{l})$ for $15 \mathrm{~min}$ at room temperature and stained with $1 \mathrm{~g} / 1$ crystal violet for $20 \mathrm{~min}$ at room temperature. Colonies of $>50$ cells were counted under a light microscope. The surviving fraction (\%) was calculated as follows: Colony forming efficiency in the experimental group/colony forming efficiency in the control group x 100; with colony forming efficiency $=$ number of colonies formed/number of cells planted $\mathrm{x} 100 \%$. A single-hit multitarget model was used to fit the survival curves and radiobiological parameters, including D0 and N, which were calculated using GraphPad Prism software (version 5.0; GraphPad Software, Inc., La Jolla, CA, USA). D0 is the radiosensitivity parameter describing the mean lethal dose. It was determined as the reciprocal slope in the semi-logarithmic survival curve. The N-value is the extrapolation value and was determined at the intersection with the Y-axis.

Western blotting and antibodies. The lung cancer cells were washed with ice-cold PBS and cell lysates were prepared using radioimmunoprecipitation assay buffer (cat. no. P0013B; Beyotime Institute of Biotechnology, Nanjing, China). Proteins were separated by SDS-PAGE, as previously described (21-23). Briefly, $20 \mu \mathrm{g}$ protein was loaded per lane, separated using 10\% SDS-PAGE gels and transferred to polyvinylidene fluoride membranes. The primary antibodies used included anti-apoptosis regulator BAX (Bax; 1:1,000; cat. no. AP1302a-ev; Abgent, Inc., San Diego, CA, USA), anti-apoptosis regulator $\mathrm{Bcl}-2$ (Bcl-2; 1:1,000; cat. no. AP1303a-ev; Abgent, Inc.) and anti- $\beta$-actin (1:1,000; cat. no. ab8227; Abcam, Cambridge, UK). Incubation with primary antibodies was overnight at $4^{\circ} \mathrm{C}$. Horseradish peroxidase-conjugated goat anti-mouse secondary antibodies (1:5,000; cat. co. sc-2031) were purchased from Santa Cruz Biotechnology, Inc. (Dallas, TX, USA). Incubation with the secondary antibody was $1 \mathrm{~h}$ at room temperature. Bands were visualized using an enhanced chemiluminescence detection kit (Amersham; GE Healthcare, Chicago, IL, USA) and analyzed with ImageJ software (V1.8.0; National Institutes of Health, Bethesda, MD, USA) for quantification.

Statistical analysis. The data was analyzed using SPSS (version 20.0; IBM Corp., Armonk, NY, USA) and GraphPad Prism software 5.0 (GraphPad Software, Inc.). The results are presented as the mean \pm standard deviation. Experiments were repeated twice with each sample run in triplicate. Comparisons between multiple groups were analyzed using one-way analysis of variance followed by a post hoc Tukey's range test. The survival fraction analysis was performed using an independent samples t-test. $\mathrm{P}<0.05$ was considered to indicate a statistically significant difference.

\section{Results}

Oridonin suppresses the proliferation of lung cancer cells in a time-and dose-dependent manner. Oridonin is a naturally derived substance with low toxicity that possesses antitumor activity against various types of cancer $(12,18,24)$. To explore the antitumor activities of oridonin on lung cancer cells, human lung cancer SPC-A-1 cells were treated with increasing concentrations of oridonin $(0-80 \mu \mathrm{m})$ for $24 \mathrm{~h}$. Cell viability was then determined by the MTT assay and the results demonstrated that the inhibition rate of oridonin on the cells gradually increased in a dose-dependent manner (all $\mathrm{P}<0.05$ vs. the $0 \mu \mathrm{m}$ oridonin group; Fig. 1A). In addition, the HCC827 cells were treated with oridonin $(0-80 \mu \mathrm{m})$ for 24 , 48 or $72 \mathrm{~h}$ and the MTT assay was performed to determine cell proliferation. Consistently, the inhibition rate increased as the concentration of oridonin increased (Fig. 1B). Notably, oridonin exhibited a marked inhibitory effect on HCC827 cell proliferation in a time-dependent manner (Fig. 1B). These results indicate that oridonin inhibits the proliferation of lung cancer cells in a time- and dose-dependent manner. As cell growth was increased and more consistent using SPC-A1 cells compared with HCC827, SPC-A1 cells were chosen for further experiments.

Irradiation inhibits cell proliferation of SPC-A-1 cells. In order to identify an appropriate irradiation dose for SPC-A-1 cells, a series of irradiation doses were used to treat the cells, which were then cultured for $24 \mathrm{~h}$. Cell viability was then determined using the MTT assay. The results demonstrated that the proliferation of SPC-A-1 cells was significantly inhibited with increasing irradiation doses (all $\mathrm{P}<0.01$ vs. the 0 Gy group; Fig. 2A). Cells were irradiated with 2, 4, 8 and $16 \mathrm{~Gy}$; the inhibition rate was $62.4 \%$ at $16 \mathrm{~Gy}$. In the following experiments, a 4 Gy irradiation dose ( $30 \%$ inhibition rate) was used to treat the lung cancer cells.

Oridonin increases the radiosensitivity of SPC-A-1 cells. An increasing concentration of oridonin (0-40 $\mu \mathrm{m})$ was used to 


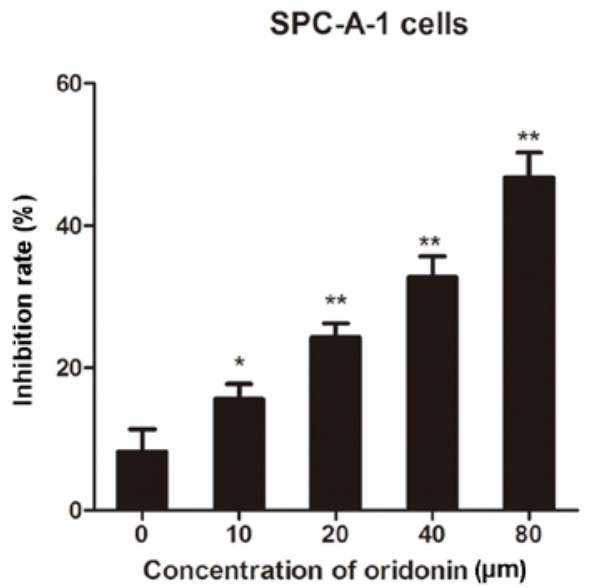

B

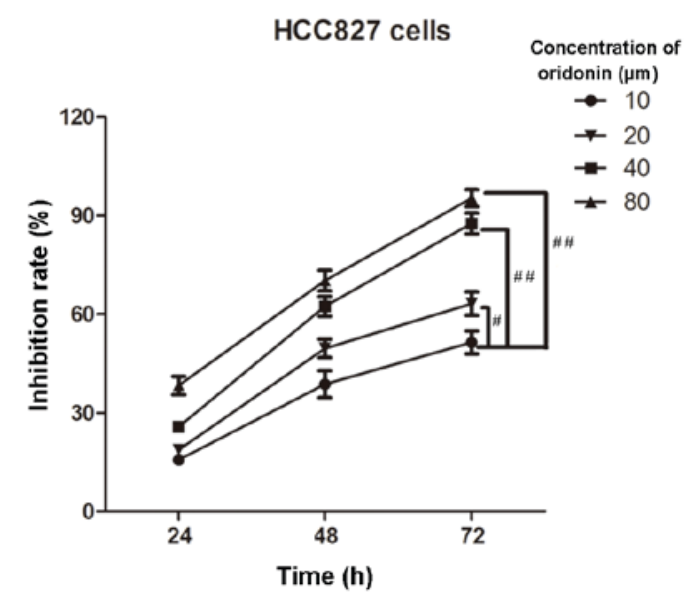

Figure 1. Oridonin suppresses the proliferation of lung cancer cells in a time- and dose-dependent manner. (A) Human lung cancer SPC-A-1 cells were treated with different concentrations of oridonin for $24 \mathrm{~h}$ and the MTT assay was performed to determine cell viability. (B) HCC 827 cells were treated with different concentrations of oridonin for 24,48 or $72 \mathrm{~h}$ and the MTT assay was performed to measure cell viability. ${ }^{*} \mathrm{P}<0.05,{ }^{* *} \mathrm{P}<0.01$ vs. the $0 \mu \mathrm{m}$ oridonin group; ${ }^{\#} \mathrm{P}<0.05,{ }^{\# \#} \mathrm{P}<0.01$.

A

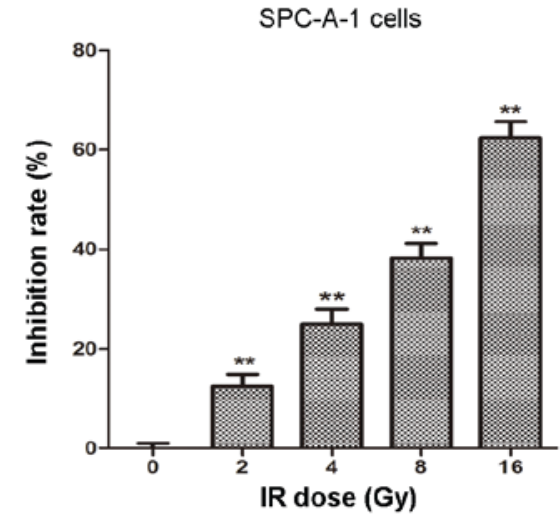

B

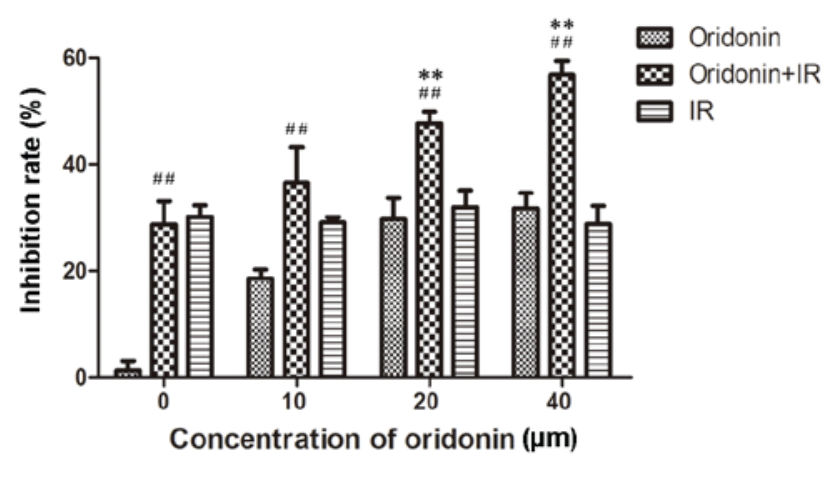

Figure 2. Oridonin increases the radiosensitivity of SPC-A-1 cells. (A) Cells were irradiated with 2, 4, 8 or 16 Gy and the inhibition rate was determined using the MTT assay. (B) Cells were pretreated with 10, 20 or $40 \mu \mathrm{m}$ oridonin for $24 \mathrm{~h}$, then each group was irradiated with 4 Gy and the MTT assay was used to detect cell viability. At $0 \mu \mathrm{m}$ oridonin, the drug was substituted with dimethyl sulfoxide and oridonin+IR served as the control group. ${ }^{* *} \mathrm{P}<0.01$ vs. 0 Gy group; ${ }^{\# \#} \mathrm{P}<0.01$ vs. oridonin group at the respective concentration. IR, irradiation.

pretreat the human lung cancer SPC-A-1 cells for $24 \mathrm{~h}$ prior to a 4 Gy irradiation dose. Subsequently, cell viability was determined using the MTT assay. As shown in Fig. 2B, the inhibition rate was significantly increased in the 20 and $40 \mu \mathrm{M}$ oridonin pretreatment groups compared with the group treated with irradiation alone $(\mathrm{P}<0.01)$.

SPC-A-1 cell survival is enhanced by oridonin treatment prior to irradiation. In order to further determine the role of oridonin on the radiosensitivity of lung cancer cells, SPC-A-1 cells were pretreated with $40 \mu \mathrm{m}$ oridonin for $24 \mathrm{~h}$ and then exposed to various irradiation doses (2, 4, 6, 8 and $10 \mathrm{~Gy})$. The results demonstrated that the survival fraction in the oridonin and irradiation treated group was lower compared with that in the irradiation alone group at all doses (Fig. 3). In the single-hit multitarget model, for its associated parameters the D0 value was $2.916 \pm 0.063$ in the oridonin pretreatment group, which was significantly decreased compared with that of $3.465 \pm 0.239$ in the group without oridonin pretreatment $(\mathrm{P}<0.05$; Fig. 3$)$. The $\mathrm{N}$ value was $2.367 \pm 0.334$ in oridonin-pretreated cells

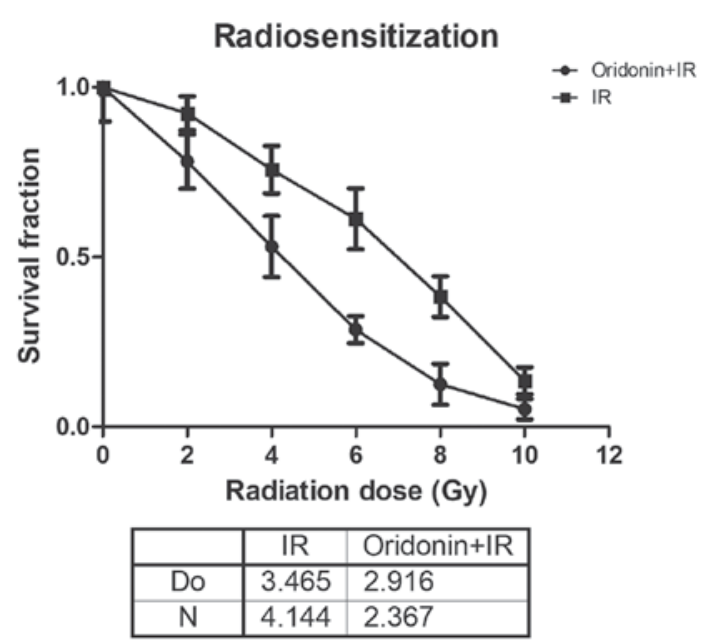

Figure 3. SPC-A-1 cell survival is enhanced by oridonin treatment prior to IR. SPC-A-1 cells were pretreated with $40 \mu \mathrm{m}$ oridonin for $24 \mathrm{~h}$ and then irradiated with 2, 4, 6, 8 and $10 \mathrm{~Gy}$. The survival rates were fitted using a single-hit multitarget model. IR, irradiation; D0, radiosensitivity parameter; $\mathrm{N}$, extrapolation value. 
A
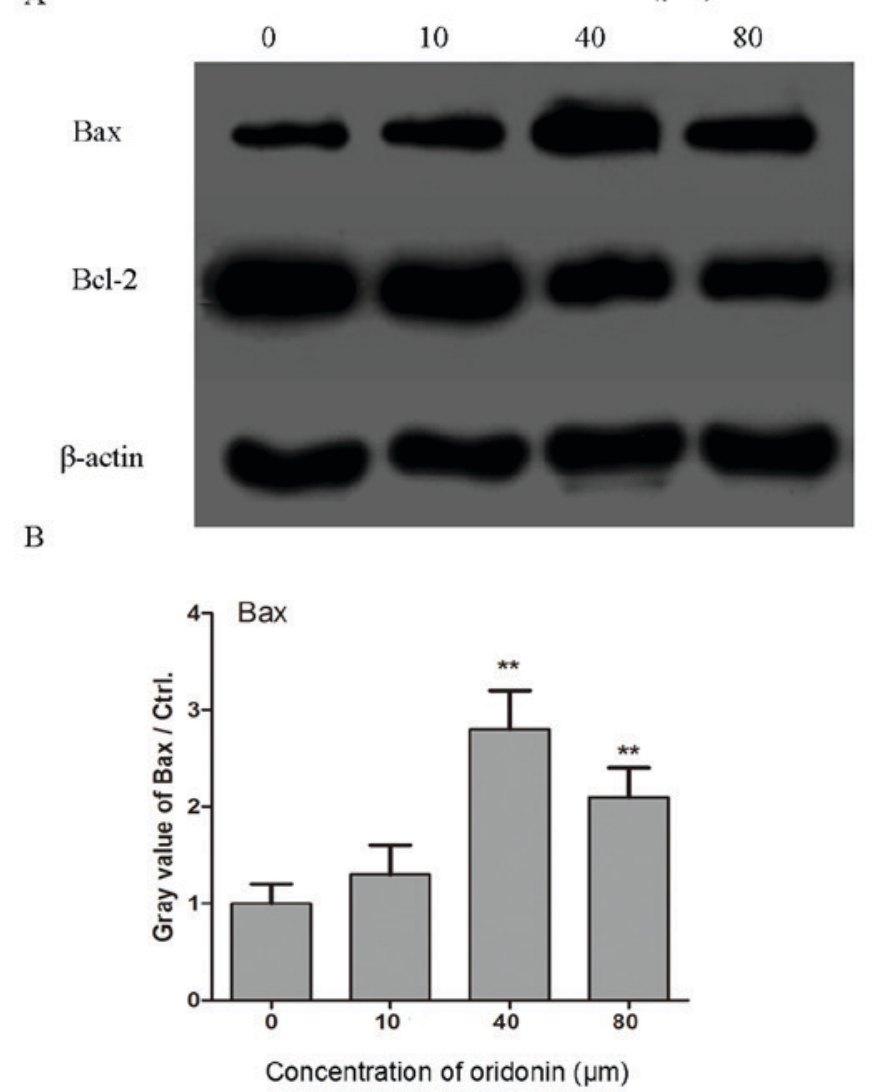

C

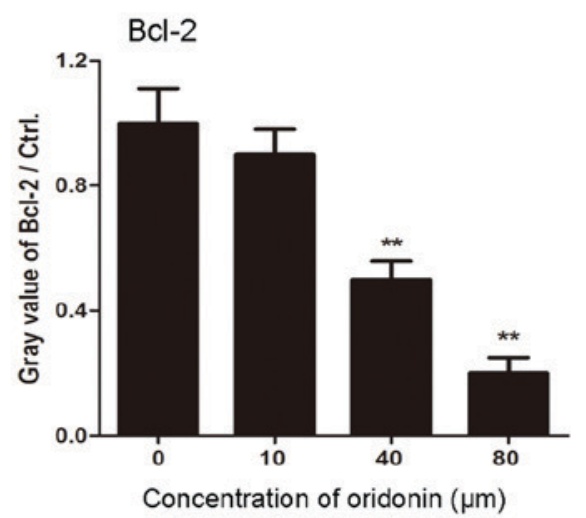

Figure 4. Oridonin promotes the expression of Bax and decreases the expression of Bcl-2 in SPC-A-1 cells. (A) Cells were treated with 10,40 or $80 \mu$ m oridonin for $24 \mathrm{~h}$, then cell lysates were prepared and the levels of Bax and Bcl-2 were determined by western blotting. The gray values of the (B) Bax and (C) Bcl-2 western blotting results were quantified. ${ }^{* *} \mathrm{P}<0.01$ vs. the $0 \mu \mathrm{m}$ oridonin group. $\mathrm{Bax}$, apoptosis regulator BAX; Bcl-2, apoptosis regulator Bcl-2.

compared with $4.144 \pm 1.519$ in the cells without oridonin pretreatment.

Oridonin promotes the expression of Bax and decreases the expression of Bcl-2 in SPC-A-1 cells. Furthermore, the underlying molecular mechanism of the effect of oridonin on lung cancer cells was investigated by western blotting analysis. The SPC-A-1 cells were treated with different doses of oridonin $(10,40$ and $80 \mu \mathrm{m})$ for $24 \mathrm{~h}$ prior to analysis. As shown in Fig. 4, the level of Bax gradually increased as the concentration of oridonin increased, up until a dose of $40 \mu \mathrm{m}$, and conversely, the level of $\mathrm{Bcl}-2$ decreased with an

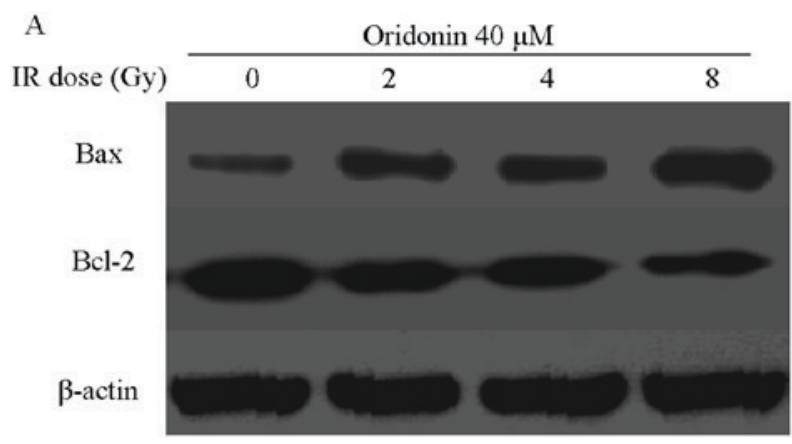

B

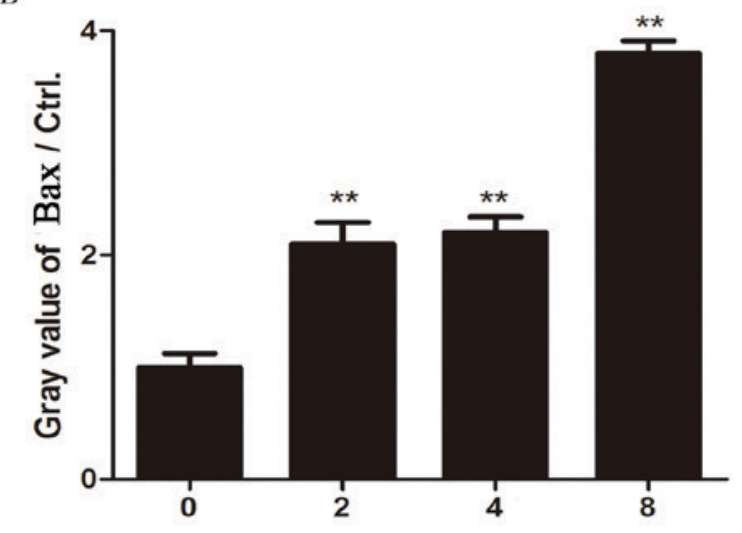

C

IR dose (Gy)

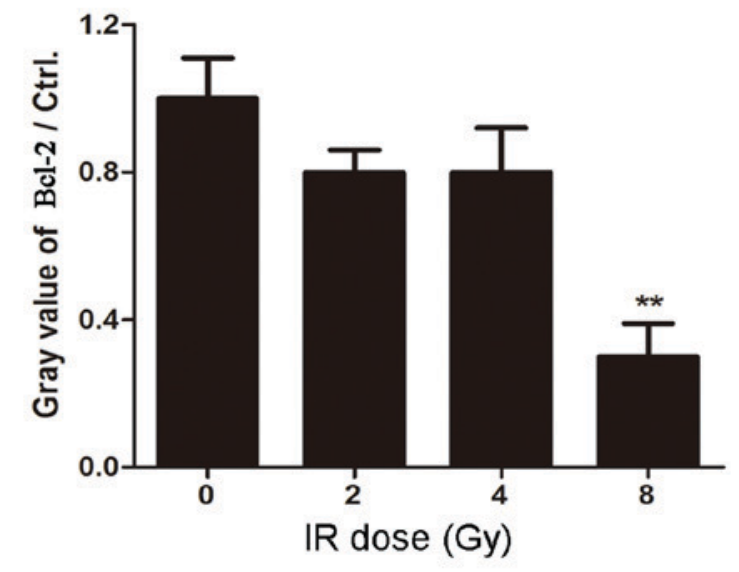

Figure 5. Oridonin in combination with IR increases the apoptosis of SPC-A-1 cells. (A) Cells were pretreated with oridonin for $24 \mathrm{~h}$ and irradiated with 2,4 or $8 \mathrm{~Gy}$, and then the levels of Bax and Bcl-2 were detected by western blotting analysis. The gray values of the (B) Bax and (C) Bcl-2 western blotting results were quantified. ${ }^{* *} \mathrm{P}<0.01$ vs. the 0 Gy group. Bax, apoptosis regulator BAX; Bcl-2, apoptosis regulator Bcl-2. IR, irradiation.

increasing concentration of oridonin. These results indicate that oridonin pretreatment promotes the apoptosis of lung cancer cells.

Oridonin in combination with irradiation increases the level of Bax and decreases the level of Bcl-2 in SPC-A-1 cells. To investigate whether pretreatment with oridonin promoted the apoptosis of lung cancer cells in response to irradiation, western blotting was performed to detect the expression levels of Bax and Bcl-2 after oridonin and irradiation treatment. SPC-A-1 cells were pretreated with oridonin $(40 \mu \mathrm{M})$ for $24 \mathrm{~h}$ and then subjected to a $0,2,4$ or $8 \mathrm{~Gy}$ irradiation dose. As shown in 
Fig. 5, the expression of Bax was increased and the expression of Bcl-2 was decreased with increasing irradiation doses. These results suggest that oridonin increases the radiosensitivity of human lung cancer cells through inducing apoptosis.

\section{Discussion}

In recent years, great progress has been made in the diagnosis of and clinical therapy for lung cancer. However, the mortality rate of patients with lung cancer remains high, with a 5-year survival rate of only $15 \%(25-27)$. Oridonin is a compound that is extracted from the traditional Chinese herb R. rubescens, which possesses anticancer properties through inhibiting proliferation and promoting apoptosis $(24,28,29)$. The present study investigated the role of oridonin in the radiosensitivity of lung cancer cells.

Two human lung cancer cell lines, HCC827 and SPC-A-1, were used as cell models of lung cancer. The human lung cancer cells were treated with different concentrations of oridonin for 24,48 or $72 \mathrm{~h}$ and cell viability was determined using the MTT assay. The results demonstrated that oridonin inhibited lung cancer cell proliferation in a time- and dose-dependent manner. Next, the lung cancer cells were exposed to different doses of radiation, which revealed that irradiation inhibited the proliferation of SPC-A-1 cells. Furthermore, different concentrations of oridonin were used to pretreat the SPC-A-1 cells for $24 \mathrm{~h}$ prior to a $4 \mathrm{~Gy}$ irradiation dose. The results demonstrated that oridonin increased the radiosensitivity of SPC-A-1 cells.

The underlying molecular mechanism of the effect of oridonin and irradiation on lung cancer cells was explored. Notably, the results demonstrated that oridonin in combination with irradiation promoted the apoptosis of SPC-A-1 cells, as the Bax/Bcl-2 ratio was increased in the cells treated with combination therapy compared with each therapy alone. $\mathrm{Bcl}-2$ is an antiapoptotic protein that is primarily located on the nuclear membrane, endoplasmic reticulum and the outer mitochondrial membrane, and inhibits the progression of X-ray-induced apoptosis (30,31). Another apoptotic effector, Bax, also belongs to Bcl-2 family. Bax can bind to Bcl-2 to form heterodimers, which promote apoptosis $(32,33)$. In the present study, treatment with oridonin prior to irradiation notably increased the ratio of $\mathrm{Bax} / \mathrm{Bcl}-2$, suggesting that apoptosis was promoted by the combination of oridonin and irradiation compared with each treatment alone. Active Bax is recruited to the mitochondria and forms pores leading to the release of cytochrome c (33). Thus, the present study hypothesized that combination treatment with oridonin and irradiation activated the mitochondrial-mediated apoptosis signaling pathway. However, the present study only detected the levels of Bax and $\mathrm{Bcl}-2$. Further studies are required to measure the apoptotic rate of lung cancer cells after oridonin treatment and irradiation. In conclusion, the results of the present study indicate that oridonin has a potential application as a radiosensitizing agent for the treatment of human NSCLC.

\section{Acknowledgements}

The authors would like to thank Professor Guanghui Cheng (Department of Radiation, China-Japan Union Hospital of Jilin University, Changchun, China) for guidance with the experiments and the publication of the work and Professor Dan Shi (Department of Radiation, China-Japan Union Hospital of Jilin University, Changchun, China) for scientific discussions. Furthermore the support of Liangyu Zhang and Fang Yang is gratefully acknowledged.

\section{Funding}

No funding was received.

\section{Availability of data and materials}

The datasets used and/or analyzed during the current study are available from the corresponding author on reasonable request.

\section{Authors' contributions}

SL and GC contributed to the conception and design of the study. SL was involved with the clinical studies. DS and FY performed the experiments and analysed the data. LZ performed the statistical analysis and prepared the manuscript. All authors read and approved the final manuscript.

\section{Ethics approval and consent to participate}

Not applicable.

\section{Patient consent for publication}

Not applicable.

\section{Competing interests}

The authors declare that they have no competing interests.

\section{References}

1. Chen J, Chen J, Wu X, Shi T and Kang M: Efficacy of targeted agents in the treatment of elderly patients with advanced non-small-cell lung cancer: A systematic review and meta-analysis. OncoTargets Ther 9: 4797-4803, 2016.

2. Yano M, Yoshida J, Koike T, Kameyama K, Shimamoto A, Nishio W, Yoshimoto K, Utsumi T, Shiina T, Watanabe A, et al: The outcomes of a limited resection for non-small cell lung cancer based on differences in pathology. World J Surg 40: 2688-2697, 2016

3. Giopanou I, Lilis I, Papaleonidopoulos V, Marazioti A, Spella M, Vreka M, Papadaki H and Stathopoulos GT: Comprehensive evaluation of nuclear factor- $\kappa \beta$ expression patterns in non-small cell lung cancer. PloS One 10: e0132527, 2015.

4. Arrieta O, Carmona A, Ramirez-Tirado LA, Flores-Estrada D, Macedo-Pérez EO, Martínez-Hernández JN, Corona-Cruz JF, Cardona AF and de la Garza J: Survival of patients with advanced non-small cell lung cancer enrolled in clinical trials. Oncology 91: 185-193, 2016.

5. Fernandez-Lopez C, Exposito-Hernandez J, Arrebola-Moreno JP, Calleja-Hernández MÁ, Expósito-Ruíz M, Guerrero-Tejada R, Linares I and Cabeza-Barrera J: Trends in phase III randomized controlled clinical trials on the treatment of advanced non-small-cell lung cancer. Cancer Med 5: 2190-2197, 2016.

6. Paleiron N, Bylicki O, Andre M, Rivière E, Grassin F, Robinet G and Chouaiid C: Targeted therapy for localized non-small-cell lung cancer: A review. OncoTargets Ther 9: 4099-4104, 2016

7. Aridgides $P$ and Bogart J: Stereotactic body radiation therapy for stage i non-small cell lung cancer. Thoracic Surg Clin 26: 261-269, 2016 
8. Jiang J, Liang X, Zhou X, Huang R and Chu Z: A meta-analysis of randomized controlled trials comparing carboplatin-based to cisplatin-based chemotherapy in advanced non-small cell lung cancer. Lung Cancer 57: 348-358, 2007.

9. D'Addario G, Pintilie M, Leighl NB, Feld R, Cerny T and Shepherd FA: Platinum-based versus non-platinum-based chemotherapy in advanced non-small-cell lung cancer: A meta-analysis of the published literature. J Clin Oncol 23: 2926-2936, 2005.

10. Forsythe B and Faulkner K: Overview of the tolerability of gefitinib (IRESSA) monotherapy: Clinical experience in non-small-cell lung cancer. Drug Saf 27: 1081-1092, 2004.

11. Wong AM, Zhang Y, Kesler K, Deng M, Burhenn L, Wang D, Moro A, Li Z and Heber D: Genomic and in vivo evidence of synergy of a herbal extract compared to its most active ingredient: Rabdosia rubescens vs. oridonin. Exp Ther Med 1: 1013-1017, 2010

12. Wu QX, Yuan SX, Ren CM, Yu Y, Sun WJ, He BC and Wu K Oridonin upregulates PTEN through activating p38 MAPK and inhibits proliferation in human colon cancer cells. Oncol Rep 35: 3341-3348, 2016

13. Shi M, Lu XJ, Zhang J, Diao H, Li G, Xu L, Wang T, Wei J, Meng W, Ma JL, et al: Oridonin, a novel lysine acetyltransferases inhibitor, inhibits proliferation and induces apoptosis in gastric cancer cells through p53- and caspase-3-mediated mechanisms. Oncotarget 7: 22623-22631, 2016.

14. Ming M, Sun FY, Zhang WT and Liu JK: Therapeutic effect of oridonin on mice with prostate cancer. Asian Pac J Trop Med 9: 184-187, 2016

15. Kang N, Cao SJ, Zhou Y, He H, Tashiro S, Onodera S, Qiu F and Ikejima T: Inhibition of caspase- 9 by oridonin, a diterpenoid isolated from Rabdosia rubescens, augments apoptosis in human laryngeal cancer cells. Int J Oncol 47: 2045-2056, 2015.

16. Wang YY, Lv YF, Lu L and Cai L: Oridonin inhibits mTOR signaling and the growth of lung cancer tumors. AntiCancer Drugs 25: 1192-1200, 2014

17. Wang S, Zhong Z, Wan J, Tan W, Wu G, Chen M and Wang Y: Oridonin induces apoptosis, inhibits migration and invasion on highly-metastatic human breast cancer cells. Am J Chin Med 41: 177-196, 2013

18. Bao R, Shu Y, Wu X, Weng H, Ding Q, Cao Y, Li M, Mu J, Wu W, Ding $\mathrm{Q}$, et al: Oridonin induces apoptosis and cell cycle arrest of gallbladder cancer cells via the mitochondrial pathway. BMC Cancer 14: 217, 2014.

19. Murayama C, Nagao Y, Sano S, Ochiai M, Fuji K, Fujita E and Mori T: Effect of oridonin, a Rabdosia diterpenoid, on radiosensitization with misonidazole. Experientia 43: 1221-1223, 1987.

20. Sagar SM: Can the therapeutic gain of radiotherapy be increased by concurrent administration of Asian botanicals? Integr Cancer Ther 9: 5-13, 2010

21. Nishitani H, Sugimoto N, Roukos V, Nakanishi Y, Saijo M, Obuse C, Tsurimoto T, Nakayama KI, Nakayama K, Fujita M, et al: Two E3 ubiquitin ligases, SCF-Skp2 and DDB1-Cul4, target human Cdt1 for proteolysis. EMBO J 25: 1126-1136, 2006.
22. Peng L, Xu Z, Zhou Y, Yang T, Liang ZQ and Zhang M: Effect of rosiglitazone on cells cycle, apoptosis and expression of Skp2 and $\mathrm{p} 27 \mathrm{Kip} 1$ in hepatocellular carcinoma cell line. Zhonghua Gan Zang Bing Za Zhi 18: 148-149, 2010 (In Chinese).

23. Schulman BA, Carrano AC, Jeffrey PD, Bowen Z, Kinnucan ER, Finnin MS, Elledge SJ, Harper JW, Pagano M and Pavletich NP: Insights into SCF ubiquitin ligases from the structure of the Skp1-Skp2 complex. Nature 408: 381-386, 2000.

24. Li Y, Wang Y, Wang S, Gao Y, Zhang X and Lu C: Oridonin phosphate-induced autophagy effectively enhances cell apoptosis of human breast cancer cells. Med Oncol 32: 365, 2015.

25. Shen H, Cao Y, Li X, Tan Y, Chen J, Yang Z, Kong Y and Yuan Y: Surgical intervention improves survival for metastatic non-small cell lung cancer patients. Medicine (Baltimore) 95: e3800, 2016.

26. Santarpia M, Rolfo C, Peters GJ, Leon LG and Giovannetti E: On the pharmacogenetics of non-small cell lung cancer treatment. Expert Opin Drug Metab Toxicol 12: 307-317, 2016.

27. Ohtaki Y, Shimizu K, Kaira K, Nagashima T, Obayashi K, Nakazawa S, Kakegawa S, Igai H, Kamiyoshihara M, Nishiyama $\mathbf{M}$ and Takeyoshi I: Risk factors associated with recurrence of surgically resected node-positive non-small cell lung cancer. Surg Today 46: 1196-1208, 2016.

28. Zhang XH, Liu YX, Jia M, Han JS, Zhao M, Ji SP and Li AM: Oridonin inhibits tumor growth in glioma by inducing cell cycle arrest and apoptosis. Cell Mol Biol (Noisy-le-grand) 60: 29-36, 2014.

29. Xu B, Shen W, Liu X, Zhang T, Ren J, Fan Y and Xu J: Oridonin inhibits BxPC-3 cell growth through cell apoptosis. Acta Biochim Biophys Sin (Shanghai) 47: 164-173, 2015.

30. Dong Y, Zheng Y, Xiao J, Zhu C and Zhao M: Regulatory effect of Bcl-2 in ultraviolet radiation-induced apoptosis of the mouse crystalline lens. Exp Ther Med 11: 973-977, 2016.

31. Zhen L, Li J, Zhang M and Yang K: MiR-10b decreases sensitivity of glioblastoma cells to radiation by targeting AKT. J Biol Res (Thessalon) 23: 14, 2016

32. Liu Q, Si T, Xu X, Liang F, Wang L and Pan S: Electromagnetic radiation at $900 \mathrm{MHz}$ induces sperm apoptosis through bcl-2, bax and caspase-3 signaling pathways in rats. Reprod Health 12: $65,2015$.

33. Mendes F, Sales T, Domingues C, Schugk S, Abrantes AM, Gonçalves AC, Teixo R, Silva R, Casalta-Lopes J, Rocha C, et al: Effects of X-radiation on lung cancer cells: The interplay between oxidative stress and P53 levels. Med Oncol 32: 266, 2015. 